\title{
Air clathrate crystals from the GRIP deep ice core, Greenland: a number-, size- and shape-distribution study
}

\author{
F. Pauer, ${ }^{1}$ S. Kipfstuhl, ${ }^{1}$ W. F. Kuns, ${ }^{2}$ H. Shoji ${ }^{3}$ \\ ${ }^{1}$ Alfred-Wegener-Institut für Polar- und Meeresforschung, P.O. Box 120161, D-27515 Bremerhaven, Germany \\ ${ }^{2}$ Mineralogisch-Kristallographisches Institut, Göttingen University, D-37077 Göttingen, Germany \\ ${ }^{3}$ Kitami Institute of Technology, Kitami 090, Japan
}

\begin{abstract}
We performed microscopic observations and a statistical study of the number, size and shape distribution of clathrates in the GRIP Greenland Ice Core Project) deep ice core, using 185 samples from a depth range of 1016-3014 m, spanning a period of 6 to $>110 \mathrm{ka} \mathrm{BP}$ and encompassing the Holocene, Wisconsin and Eemian periods. The number concentration of the clathrates varied considerably with climatic changes. It was possible to detect the rapid climatic oscillations in the last glacial between 13 and $110 \mathrm{ka}$ BP, the Dansgaard-Oeschger cycles, in the number-concentration profile of clathrates. The mean volume of clathrates is less clearly influenced by climatic factors, with a tendency towards greater volumes in warmer periods, but also a growth of clathrates with depth could be detected. This growth rate was calculated to be $3.1 \times 10^{-12} \mathrm{~cm}^{3} \mathrm{a}^{-1}$. The amount of gases captured in the clathrates is estimated to be significantly smaller than the total amount of air determined by gas-concentration measurements. This points to diffusion processes of atmospheric gases within the ice matrix.
\end{abstract}

\section{INTRODUCTION}

The transition from snow to firn involves densification and formation of porous channels, which allow the exchange of gases contained in them with the atmosphere. At the firnice transition these open pores are closed off, and individual bubbles form in which atmospheric air is captured. At greater depths, depending on the temperature of the ice, the increasing hydrostatic pressure enters the stability range of air clathrates. Miller (1969) predicted their existence in polar ice sheets from the consideration of their thermodynamic properties, which was confirmed by their discovery by Shoji and Langway (1982). Below the depth corresponding to their dissociation pressure at a given temperature, more and more clathrates begin to form with increasing pressure as the depth increases, until the transition of air bubbles to clathrates is complete. This range of coexistence of air bubbles and clathrates is called the transition zone and is stretched over hundreds of metres of depth - between $1000 \mathrm{~m}$ (observation of the first clathrates) and $1500 \mathrm{~m}$ (disappearance of bubbles) in the GRIP (Greenland Ice Core Project) deep ice core - corresponding to a time interval of $4.2 \mathrm{ka}$, from 5.6 to $9.8 \mathrm{ka}$ BP. For clathrate formation, nucleation is necessary to enable the lattice transformation to start. This is assumed to take place not right after the $p-T$ conditions have been met, but over a longer depth and time range (Uchida and others, 1992, 1994c; Ikeda and others, 1993). In contrast to this model, Price (1995) argued that the long transition period was the result of diffusion of gas and water molecules. According to him, the diffusion of water molecules through the clathrate lattice takes an extremely long time, hence the long period of coexistence of clathrates and air bubbles. However, no inclusions in a transition state from air bubble to clathrates have been detected in the transition zone. We have observed only those clathrates transforming back to bubbles, clearly to be recognized by the opening in only one sector of a clathrate and the cracks that form around the bubble. In a field investigation on clathrates in the transition zone of the NGRIP (North Greenland Ice Core Project) ice core immediately after core retrieval, no clathrates in a transitional state were observed. The inclusions encountered were either primary air bubbles or completely transformed clathrates, which refutes the hypothesis that diffusion was the reason for the coexistence of clathrates and air bubbles.

The influence of the dissociation of air clathrates on the ice-core quality, which causes the brittleness of the ice, was investigated by Uchida and others (1994b). The part of the ice core in which clathrates decompose soon after core retrieval is called the brittle zone.

Hondoh and others (1990) showed in an X-ray study that natural air clathrates crystallize in the von Stackelberg type II structure. The presence of nitrogen and oxygen was evidenced by Nakahara and others (1988), revealing an $\mathrm{N}_{2} / \mathrm{O}_{2}$ ratio of 1.7. This molecular ratio has been the focus of attention, with compositions varying between oxygen enrichment (Nakahara and others, 1988; Fukazawa, 1996b), the finding of an overall situation close to the atmospheric value of 3.7 (Pauer and others, 1995, 1997) and strong oxygen depletion (personal communication from H. Fukazawa, 1996). However, the overall value of 3.7 determined as the average of 144 clathrates in samples from 21 different depths in the GRIP ice core does not reflect the strong variability of the $\mathrm{N}_{2} / \mathrm{O}_{2}$ ratios that we find between individual clathrates in a given sample or between the average values for clathrates from a certain depth. This variation is found in a range between 2.1 (for a sample from $1219 \mathrm{~m}$ depth) and $4.3(2431 \mathrm{~m})$. Even in 
different clathrate specimens from the same sample we obtained deviations of about $10 \%$ from the average value.

Whereas in a previous study in our laboratory a variation of the nitrogen/oxygen ratio within clathrates and on their decomposition could not be shown (Pauer and others, 1996), Fukazawa and others (1996a) detected different molecular ratios in different positions in a clathrate specimen, suggesting an oxygen enrichment in the marginal areas of a clathrate specimen. It is still an open question what might cause fractionation of the constituents of the atmosphere. Apparently, there is an implication of fractionation as the consequence of the different dissociation pressures of oxygen and nitrogen clathrate, i.e. 120 vs 160 bar, respectively, at $273.15 \mathrm{~K}$ (Van Cleeff and Diepen, 1960, 1965). But this does not account for the variability of the $\mathrm{N}_{2} / \mathrm{O}_{2}$ ratio in different clathrate specimens from the same depths. Neither does it explain the long-term coexistence of clathrates and air bubbles. This, in turn, means that many factors might influence the composition of clathrates, with temperature, i.e. climatic changes in the case of polar ice sheets, being one of them.

The effect of clathrates on the growth rate of ice grains was investigated in Uchida and others (1993). According to this work, a large quantity of the clathrates is located on grain boundaries and acts as a barrier to grain-boundary migration.

The influence of climate on the number concentration, the volume concentration and the mean volume of clathrates was shown by Uchida and others (1994a) in a series of 34 samples from the Vostok deep ice core, Antarctica. In that study, it was found that number concentrations in cold periods were up to three times as high as in warm periods, while the volume concentrations in warm periods were about $30 \%$ higher than in cold periods. It was also shown that the mean volume of clathrates grows with depth. In a preliminary study including 27 samples, we showed that the number concentration is correlated with climate also for the GRIP core, with many clathrates (up to $1250 \mathrm{~cm}^{-3}$ ) in cold periods and significantly fewer in warmer periods (about 200-400 $\mathrm{cm}^{-3}$ ) (Pauer and others, 1997).

An overview of transformation of air bubbles to clathrates, clathrate nucleation and growth, and diffusion processes is given in Hondoh (1996).

The purpose of this paper is to investigate whether the number concentration of clathrates and their size and shape distribution reflect climatic conditions.

\section{RESULTS AND DISGUSSION}

\section{Sample preparation}

In the field, the ice cores were kept between $-15^{\circ}$ and $-30^{\circ} \mathrm{C}$ for the first, non-destructive experiments. After shipping to Bremerhaven, the crude samples were stored at $-30^{\circ} \mathrm{C}$ in a storage room before they were cut and microtomed into samples about $16 \mathrm{~mm}$ thick; the length of the sample was typically $30 \mathrm{~mm}$, its width $15 \mathrm{~mm}$. The sample preparation and the establishment of the statistical data were performed in a cold laboratory at $-20^{\circ} \mathrm{C}$.

The samples were kept uncovered for a period of 24 hours, when sublimation helped to produce a smoother surface after microtoming. They were then frozen on a microslide with supercooled water drops. The top of the sample was covered with a thin cover-glass plate. Thin layers of silicone oil were applied between sample and glass surfaces, allowing clear images of the clathrates to be observed under a microscope.

\section{Methods}

The clathrate numbers and dimensions were determined under a microscope connected to a video camera. In this way the image was transmitted to a monitor, whose area and the $z$ axis of the sample defined the ice volume in which the clathrates were counted and measured. Clathrates in the samples were identified by the Becke test as employed by Shoji and Langway (1982), and their shapes were classified into the four different categories spherical, elongated, faceted polyhedral and irregular (Fig. 1). The elongated clathrates were distinguished from the spherical ones by defining the longer horizontal dimension as being more than twice as long as the shorter. We did not follow the classification into six different categories established by Uchida and others (1994a), as the distinction between the three types spherical, oval and rod-like, on the one hand, and faceted and polyhedral, on the other, is rather arbitrary in our investigation, as the transitions within the two sets of categories are smooth.
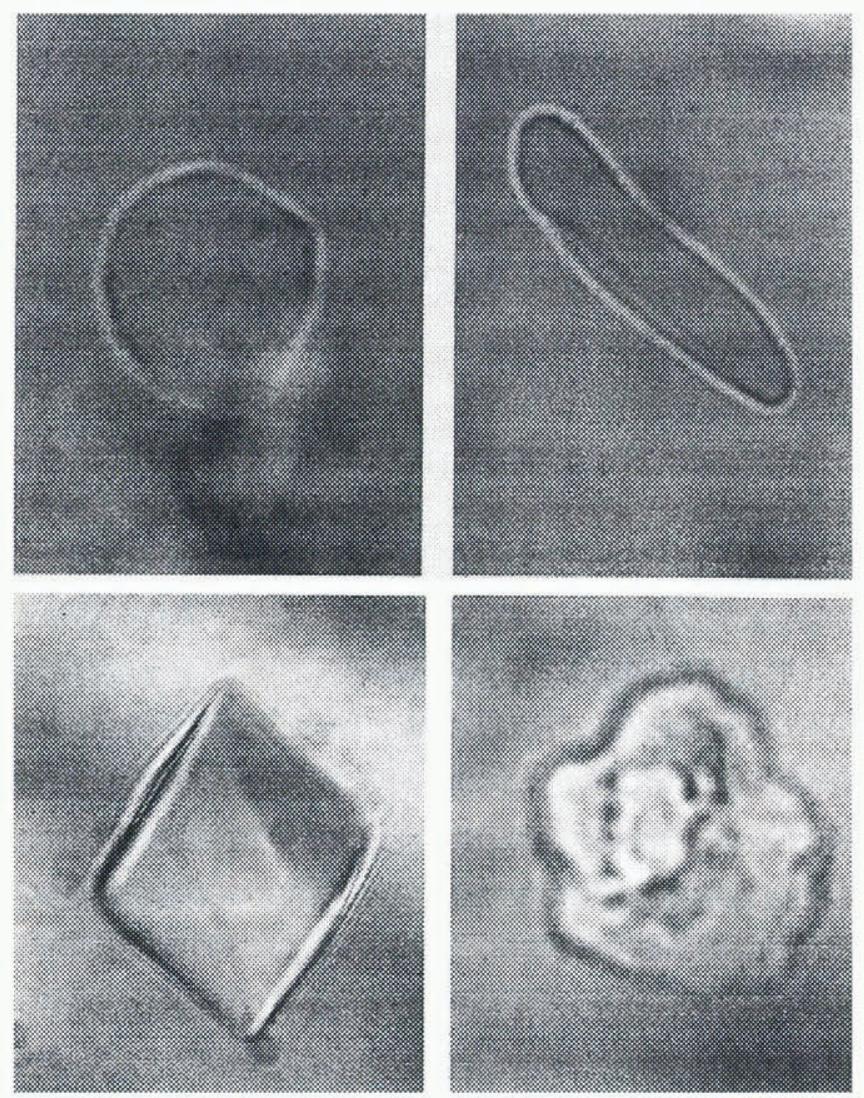

Fig. 1. Classification of clathrates; $N_{\mathrm{t}}$ denotes the total, $N_{\mathrm{s}}$ the spherical (top left), $N_{\mathrm{e}}$ the elongated (top right), $N_{\mathrm{f}}$ the faceted (bottom left) and $N_{\mathrm{i}}$ the irregular (bottom right) number concentration.

For a statistically representative study, about 200 clathrates in each sample were counted and their maximum (a) and minimum (b) horizontal diameters measured. For the volume calculation of the clathrates, $V_{\mathrm{cl}}$, we assumed the vertical dimension (c) to be the same as the shorter horizontal dimension, to form an ellipsoid. This assumption could be justified in a tomographic study of typical clathrates, in which we could see that the longest dimension of an elongated clathrate was in a horizontal dimension. The volume 
of the occluded gas, $V_{\text {gas }}$, (STP) was calculated assuming a general occupation $y$ (denoted $\alpha$ in Hondoh and others, 1990, and Uchida and others, 1994a) of the clathrate cages of $80 \%$, as determined in an X-ray experiment by Hondoh and others (1990), regardless of sample depth and age or clathrate size and shape, to facilitate comparison with the values published by Uchida and others (1994a); the actual values may be slightly higher, presumably $84-92 \%$, depending on temperature and pressure, as estimated from our first neutron-diffraction experiments on synthetic oxygen and nitrogen clathrates (see below):

$$
V_{\mathrm{cl}}=\frac{4}{3} \pi \frac{a}{2}\left(\frac{b}{2}\right)^{2}
$$

where $a$ is the longer and $b$ the shorter horizontal dimension.

$$
V_{\text {gas }}=\frac{V_{\text {cl }} R T y N_{\text {cage }}}{a^{3} p N_{\mathrm{a}}}
$$

where $N_{\text {cage }}$ is the number of cages per unit cell (24 in the type II structure), $R$ is the gas constant $\left(8.314 \mathrm{~J} \mathrm{~mol}^{-1} \mathrm{~K}^{-1}\right)$, $T$ is the temperature, $y$ is the site-occupancy factor, $a$ is the lattice constant, $1.72 \mathrm{~nm}$ for air clathrates, $p$ is the gas pressure, and $N_{\mathrm{a}}$ is Avogadro's number. $T$ and $p$ are taken to be the standard values of $273 \mathrm{~K}$ and $1.013 \times 10^{5} \mathrm{~Pa}$, respectively.

A larger number of samples was used for the total number-concentration than for the volume- and shape-distribution profile because during the course of the study we found that the number concentration was greatly influenced by climatic factors, whereas the shape distribution, the mean clathrate volume and the total gas-volume concentrations followed much smoother tendencies. This is why we considered it more efficient to focus our attention on the total number of clathrates in those parts of the core where climatic variations were strongest; this is particularly true for the Dansgaard-Oeschger cycles (Dansgaard and others, 1993). Here a resolution as high as possible is required in order to establish a relationship between the occurrence of clathrates and climate. Altogether, 185 samples were used for the total number-concentration profile, of which 106 samples were included in the size- and shape-distribution profile.

\section{Results}

The total number concentration and the $\delta^{18} \mathrm{O}$ profile (Dansgaard and others, 1993) are plotted against depth in Figure $2 \mathrm{a}$, and the relative contributions of the different shapes, $N_{\mathrm{x}} / N_{\mathrm{t}}$, are plotted in Figure $2 \mathrm{~b}-\mathrm{e}$.

A qualitative interpretation of the number-concentration profile shows that the first part of the core between 1100 and $1500 \mathrm{~m}$ shows low clathrate-number concentrations and significant amounts of bubbles that, from their shapes and the cracks round them, were identified as secondary air bubbles from clathrate decay after core retrieval. This means that for this part of the core a reasonable interpretation of the clathrate numbers in terms of climatic changes requires the (complicated) reconstruction of the original number of clathrates before decomposition. This is also true for the shape-contribution plots (Fig. 2b-e), in which the proportions of the individual shapes are the result of very few clathrates counted in this depth range. Thus, for the interpretation of the clathrate-formation process (e.g. to answer the question whether one air bubble transforms to one clathrate), the GRIP ice-core samples are unsuitable.

The region from 1700 to $2800 \mathrm{~m}(13-110 \mathrm{ka} \mathrm{BP})$ shows a fast fluctuation of $N_{\mathrm{t}}$, generally following the pattern of $\delta^{18} \mathrm{O}$. The first drop in the clathrate number below the transition zone at depth around $1700 \mathrm{~m}$ reflects the first interstadial (Boelling), in which four samples correspond to the $\delta^{18} \mathrm{O}$ profile reasonably well. The following 13 interstadials (IS) can be detected in a drop of the clathrate-number concentration: $1,7,11,12,13,14,15,16,18,20,21,23,24$. Also, during the Eemian, we find low values in the number-concentration profile, where the $\delta^{18} \mathrm{O}$ values are high (about $-32 \%$ ). A prominent feature here is a rapid oscillation between 2805 and $2830 \mathrm{~m}$ : the low $\delta^{18} \mathrm{O}$ value $(-38.1 \%)$ is reflected in a number concentration of $760 \mathrm{~cm}^{-3}(2806 \mathrm{~m})$, followed by a high $\delta^{18} \mathrm{O}$ value of $-32.2 \%$ o $\left(220 \mathrm{~cm}^{-3}\right.$ at $\left.2812 \mathrm{~m}\right)$, which gives way to a low $\delta^{18} \mathrm{O}$ value of $-37.4 \%$ at $2828 \mathrm{~m}$ with an increase of the clathrate number $\left(450 \mathrm{~cm}^{-3}\right)$.

The only interstadials representing a mismatch between clathrate-number concentration and $\delta^{18} \mathrm{O}$ values are IS 17 and 19 . For these the clathrate concentrations are fairly high $\left(600-850 \mathrm{~cm}^{-3}\right)$. For IS $2,4,5,6,8$ and 9 no ice-core samples were available, and there were hardly any for IS 3, 10 and 22 . The low $\delta^{18} \mathrm{O}$ value $(-42.0 \%$ ) between IS 3 and 4 is not in agreement with the sample from $2035 \mathrm{~m}$ depth with its low number concentration of $290 \mathrm{~cm}^{-3}$. Similarly, the samples from $1826 \mathrm{~m}\left(380 \mathrm{~cm}^{-3}\right), 1958 \mathrm{~m}\left(600 \mathrm{~cm}^{-3}\right), 2101 \mathrm{~m}\left(570 \mathrm{~cm}^{-3}\right)$,

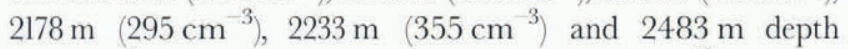
$\left(680 \mathrm{~cm}^{-3}\right)$ are not in agreement with rather low $\delta^{18} \mathrm{O}$ values, although in all cases the values are considerably higher than those of the neighbouring samples, which can only be detected in a plot with a wider resolution. It is conceivable that a short warm period is reflected in these samples, which is smoothed out in the bag averages of the $\delta^{18} \mathrm{O}$ values (see below).

A very good agreement between the number-concentration and $\delta^{18} \mathrm{O}$ values is evidenced by individual samples or groups of samples that reflect sharp drops or increases in the $\delta^{18} \mathrm{O}$ curve. These can be detected at $2420 \mathrm{~m}, 2459-2460 \mathrm{~m}$ (three samples), 2587-2588 $\mathrm{m}$ (four samples), $2633 \mathrm{~m}$ (two samples), 2756-2761 m (five samples), 2778-2783 m (four samples), 2805-2812 m (five samples), 2915-2917 m (four samples) and 2929-2930 $\mathrm{m}$ depth.

A contradiction between clathrate-number concentration and $\delta^{18} \mathrm{O}$ values is observed for the samples from 1716 , 2035, 2079, 2295, 2380, 2382, 2398, 2412, 2662 and $2859 \mathrm{~m}$ depth. However, for all these samples, the deviation is on the side of too few clathrates. No case was observed in which there are many clathrates in a warm climatic period.

It has to be borne in mind that the $\delta^{18} \mathrm{O}$ values are averages of $55 \mathrm{~cm}$ core pieces ("bags"), resulting in a smoothed $\delta^{18} \mathrm{O}$ profile. Our samples are from $5 \mathrm{~cm}$ fragments of a given bag number, possibly with different $\delta^{18} \mathrm{O}$ values, which might account for some mismatch in the $N_{\mathrm{t}}$ profile.

The total number profile is mainly determined by the number of spherical clathrates, with percentages of about 40-95\%, increasing with depth. Two outliers (1199 and $1508 \mathrm{~m}$ ) are the result of very few clathrates left in these samples; this is why the values in the depth range 1100 $1600 \mathrm{~m}$ are not statistically representative. The number of elongated clathrates follows roughly the same trend, but decreases with depth. Faceted clathrates show a shallow maximum at a depth of around $2400 \mathrm{~m}$, whereas no clear trend is observed for irregular clathrates, with values around $15 \%$. The decrease in $N_{\mathrm{e}}$ is accompanied by an increase in $N_{\mathrm{s}}$, as demonstrated in Figure 3, where the long and short dimensions are plotted against age. We have calculated the 



Fig. 2. (a) Number-concentration profiles and the $\delta^{18} O$ profile of the GRIP ice core; note that the $\delta^{18} O$ curve is inverted to facilitate visual correlation with the number-concentration profile; inset shows number of primary air bubbles plotted against depth in the depth regions before clathrate formation. ( $b$-e) Contribution of individual shapes to total number-concentration profile $\left(N_{\mathrm{x}} / N_{\mathrm{t}}\right)$; (b) showe relative contribution of spherical, (c) that of elongated, (d) that of faceted and $(e)$ that of irregular clathrates. 


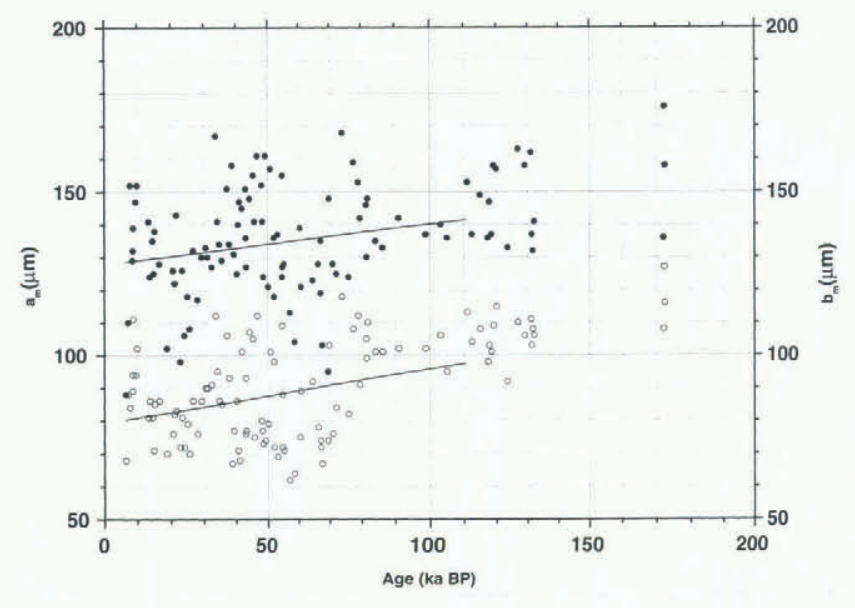

Fig. 3. Long (a) and short (b) dimensions of clathrates; lines represent calculated growth rates for the interval 10 $110 \mathrm{ka} \mathrm{BP}$; beyond this age the time-scale is considered uncertain.

increase of these dimensions as a function of age only as far as $110 \mathrm{ka}$ BP because the GRIP chronology is reliable only as far as this; beyond this depth the stratigraphy might be disturbed owing to ice flow (Taylor and others, 1993).

Whereas for the age range of the GRIP chronology (until $110 \mathrm{ka} \mathrm{BP}$ ) the longer horizontal dimensions show values of about $120-160 \mu \mathrm{m}$ with a growth rate of about $1.2 \times 10^{-4} \mu \mathrm{m}^{3} \mathrm{a}^{-1}$, the shorter ones show a higher growth rate of $1.7 \times 10^{-4} \mu \mathrm{m}^{3} \mathrm{a}^{-1}$, with values of $60-110 \mu \mathrm{m}$. If we use the data for the whole core down to $2916 \mathrm{~m}$ (about $170 \mathrm{ka} \mathrm{BP}$ ), we obtain higher growth rates of $1.5 \times 10^{4}$ and $2.1 \times 10^{4} \mu \mathrm{m}^{3} \mathrm{a}^{-1}$, respectively, with a greater age uncertainty due to the disturbances in this part of the core. This means that the clathrates not only become more spherical, they also grow substantially. In the deepest parts of the core, however, the disappearance of clathrates is observed. Whereas at $2640-2800 \mathrm{~m}$ we find clathrate numbers of about $300-500 \mathrm{~cm}^{3}$, below $2860 \mathrm{~m}$ they drop below $300 \mathrm{~cm}^{-3}$, with a minimum of about $55 \mathrm{~cm}^{-3}$ at $3014 \mathrm{~m}$. For the sample from $3014 \mathrm{~m}$, we also see a decrease of the mean clathrate volume to a low value of $0.5 \times 10^{6} \mu \mathrm{m}^{3}$, suggesting a disintegration of clathrates at this depth, while the values for the samples from $2915.1 \mathrm{~m}$ $\left(1.2 \times 10^{6} \mu \mathrm{m}^{3}\right), 2915.6 \mathrm{~m}\left(2.0 \times 10^{6} \mu \mathrm{m}^{3}\right)$ and $2916.1 \mathrm{~m}$ depth $\left(1.6 \times 10^{6} \mu \mathrm{m}^{3}\right)$ still indicate active growth.

The correlation of the clathrate profiles with $\delta^{18} \mathrm{O}$ can be seen in Figure 4a; we observe a decreasing number of clathrates with increasing $\delta^{18} \mathrm{O}$ values $\left(r^{2}=0.57\right.$ for all 185 samples). This is not meant to reflect a linear correlation between climate and clathrate numbers. First, $\delta^{18} \mathrm{O}$ is only a temperature indicator and does not necessarily reflect all climatic changes. Secondly, because of its complexity the procedure we have employed allows only a limited resolution of the number-concentration curve. Nevertheless, the qualitative agreement between the two curves is striking.

Similarly, a trend towards larger clathrates with higher $\delta^{18} \mathrm{O}$ values is displayed in Figure $4 \mathrm{~b}\left(r^{2}=0.37\right.$ for the 106 samples included in the volume calculation), while there is no clear trend in the $V_{\text {gas }}$ vs $\delta^{18} \mathrm{O}$ plot (Fig. 4c), with hardly any correlation in a linear fit $\left(r^{2}=0.27 ; 106\right.$ samples). For this calculation, the site occupancy $y$ is taken to be $80 \%$, to facilitate a comparison with the results in Uchida and others (1994a) (cf. the discussion about a pressure-dependent occupancy for nitrogen clathrates below).
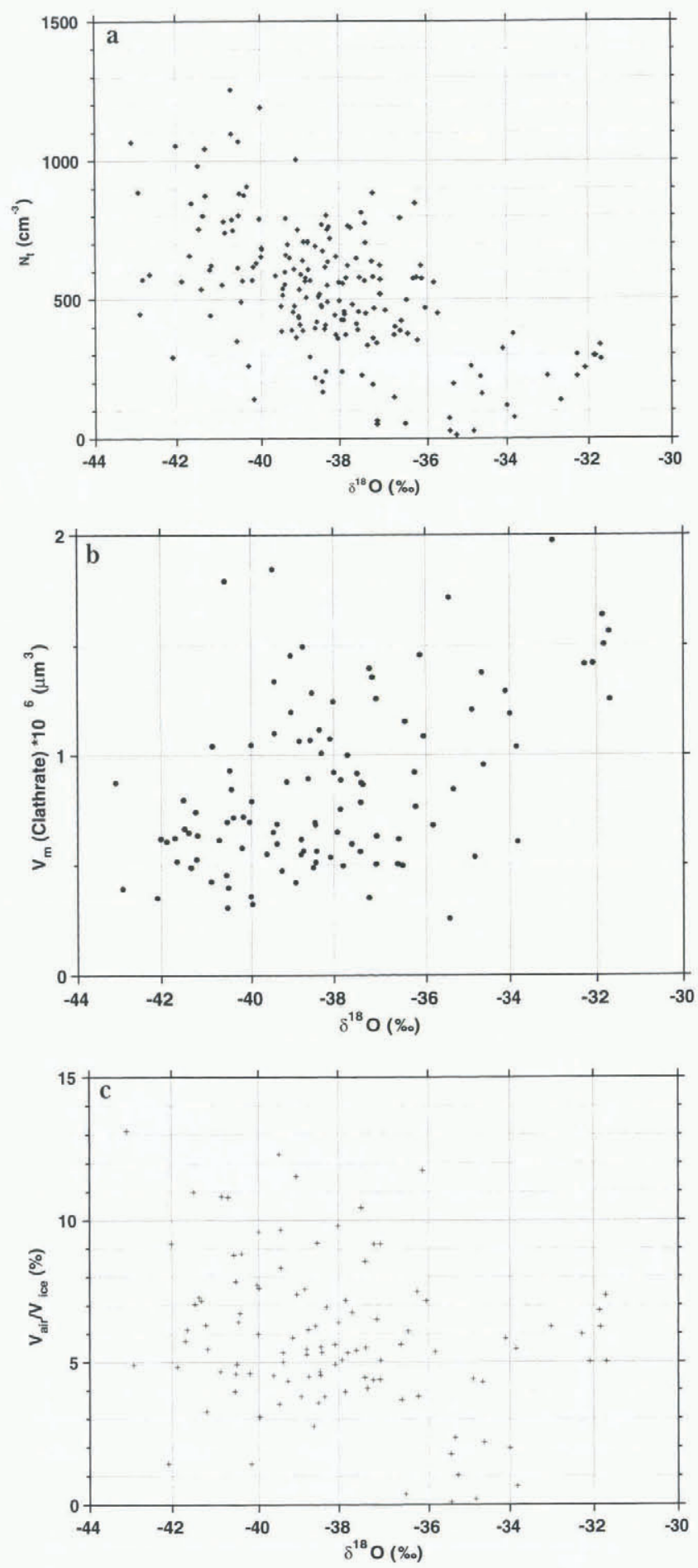

Fig.4. (a) Correlation between $N_{\mathrm{t}}$ and $\delta^{18} \mathrm{O}$; (b) correlation between $V_{\mathrm{m}}$ and $\delta^{18} \mathrm{O} ;(\mathrm{c})$ correlation between $V_{\text {gas }} / V_{\mathrm{ice}}$ and $\delta^{18} \mathrm{O}$.

\section{Discussion}

\section{Variation of $N$ and $V_{\mathrm{m}}$ with depth}

Generally it is assumed that clathrates form from individual air bubbles, as is observed in synthetic clathration experiments (Uchida and others, 1992, 1994d). According to this model, the number concentration of clathrates would be of the same order of magnitude as that of air bubbles. In the upper parts of the core in which no clathrates have formed, we have determined the number concentration of bubbles. The inset in Figure 2a shows that the number of bubbles (around $300 \mathrm{~cm}^{-3}$ ) in the depth range 100-1000 $\mathrm{m}$ roughly corresponds to the number of clathrates in those parts of the core with similar $\delta^{18} \mathrm{O}$ values (about $-35 \%$ ). 
Figure 5 shows the general trend of an increase of $V_{\mathrm{m}}$ with age, although a fluctuation, which is slightly correlated with climatic variations, can be detected (cf. Fig. 4b). This increase in volume points to growth processes on the way to the bottom of the ice sheet. Dating the samples with the GRIP ice-core chronology (Dansgaard and others, 1993), we can estimate the growth rate $\left(\mathrm{d} V_{\mathrm{m}} / \mathrm{d} t\right)$ from the linear fit in the $V_{\mathrm{m}}$ vs age plot (Fig. 5) to be $3.1 \times 10^{-12} \mathrm{~cm}^{3} \mathrm{a}^{-1}$ using data only until $110 \mathrm{ka}$ BP (see above), with a growth rate of $5.1 \times 10^{12} \mathrm{~cm}^{3} \mathrm{a}^{-1}$ for all data. It has been demonstrated above that the number of elongated clathrates decreases on the way down, resulting in a higher number of spherical clathrates. In Figure 3, it was shown that the shorter dimension $b_{\mathrm{m}}$ (mean value of a sample) increases at a greater rate $\left(\mathrm{d} b_{\mathrm{m}} / \mathrm{d} t=1.7 \times 10^{4} \mu \mathrm{m} \mathrm{a}^{-1}\right)$ than the longer dimension $a_{\mathrm{m}}$ ( $\left.\mathrm{d} a_{\mathrm{m}} / \mathrm{d} t=1.2 \times 10^{-4} \mu \mathrm{m} \mathrm{a}^{-1}\right)$, thus contributing to the clathrate growth to a significantly greater extent. In our calculation this is a square factor, according to Equation (1).

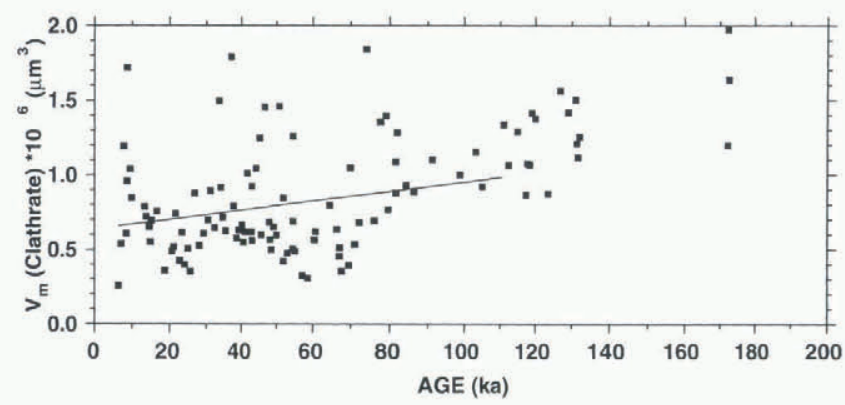

Fig. 5. $V_{\mathrm{II}}$ vs age; line represents calculated growth rate for the interval 10-110 ka BP; beyond this age the time-scale is considered uncertain.

The decrease in the number of clathrates, in the deepest part of the Vostok core (to values around $300 \mathrm{~cm}^{-3}$ at depths of 2452 and $2542 \mathrm{~m}$ ), observed by Uchida and others (1994a), was accompanied by higher $V_{\mathrm{m}}$ values. This indicates that growth is still active in this part of the Vostok core, as seems to be the case for our values in the depth range 2915-2917 m.

Two possible mechanisms need to be considered to account for this observation: diffusion of gases may occur, leading to a transformation of gas molecules and the ice matrix at the ice-clathrate boundary and, thus, in clathrate growth. The possibility of smaller clathrates disintegrating in the vicinity of larger ones has been considered and described by Uchida and others (1994d), with theoretical gasdiffusion rates calculated to be two orders of magnitude smaller than that of $\mathrm{H}_{2} \mathrm{O}$ molecules. Another process taking place in polar ice sheets is the thinning of annual layers on vertical compression, which results in the decrease of the vertical distance between clathrates and eventually to coalescence.

The growth rate in the GRIP ice core calculated above is smaller than that of the Vostok core $\left(6.7 \times 10^{-12} \mathrm{~cm}^{3} \mathrm{a}^{-1}\right)$, as published by Uchida and others (1994a). Given that the ice temperature in the Antarctic ice sheet is considerably lower than that in central Greenland, these temperatures give rise to a higher number of clathrates, which leads to a smaller average distance between clathrates. This means a greater probability that clathrates will merge, resulting in larger clathrates, as well as a smaller path for gases to diffuse through the ice matrix between clathrates, leading to the disintegration of smaller clathrates in favour of bigger ones. Both mechanisms appear to be in agreement with the observed growth rates.

The sample from $3014 \mathrm{~m}$ with its unusually low $N_{\mathrm{t}}$ and $V_{\mathrm{m}}$ values and an extremely low gas content of $0.37 \%$ (see below) provides the first evidence for the disintegration of clathrates in the deepest parts of the core. The driving force behind the disappearance of clathrates below a certain depth, i.e. above a certain pressure, might be the minimization of total volume, in addition to the absence of surface energies. In Kuhs and others (1997), the compressibility of type II clathrate was calculated to be slightly smaller than that of hexagonal ice. Additionally, the strong compression of gases under pressures encountered in deeper parts of ice sheets may cause the sum of ice volume and gas volume to be smaller than that of the volume of a clathrate consisting of the same molecules. Thus, clathrates may no longer constitute the thermodynamically stable configuration compared with the gases dissolved in the ice matrix.

\section{Comparison of $V_{\text {gas }}$ with the total gas content}

In most of the samples, $V_{\text {gas }}$ is considerably lower than the total gas amount in the ice (Raynaud and others, 1997), which is represented in Figure 6. Here, a comprehensive description is given for the methods employed for the total gas-concentration measurements. In this paper, we take the relative volume concentrations $\left(\mathrm{cm}^{3}\right.$ gas per $\mathrm{cm}^{3}$ ice $)$ after conversion of the ice-mass term into ice volume using a constant ice density of $0.92 \mathrm{~g} \mathrm{~cm}^{-3}$, to facilitate comparison with our results.

The general trend observed here is that the average amount of air contained in the clathrates (resulting in a $V_{\text {gas }} / V_{\text {ice value of }} 6.2 \pm 2.4 \%$ ) is about $35 \%$ lower than the average of the total gas content in the ice (resulting in a $V_{\text {gas }} / V_{\text {ice }}$ value of $9.6 \%$ by volume) obtained from the values plotted in Figure 6. Seven of the 106 samples show gas contents in the clathrates that are higher than their total gas content. These results are probably due to erroneous calculations of the total clathrate volume in a sample as a consequence of the existence of large, flat clathrates and, accordingly, the wrong estimation of the dimension in the $z$ axis of the microscope.

Following the discussion on fractionation of atmospheric components due to enclathration, the ability of gases to dissolve in the ice matrix is a prerequisite for fractionation to occur if the total composition of the air constituents is very close to the atmospheric value, which was determined by Raynaud and Delmas (1975). However, our assumption of a uniform degree of filling of $80 \%$ should be replaced by the values that we actually determine from neutron-diffraction experiments on synthetic air clathrates. For thermodynamic reasons the cage occupancy of clathrates $(y)$ has to be considered a function of temperature and pressure; it cannot be calculated from the ratio of the total gas content $\left(V_{\text {gas }}\right)$ and the total clathrate volume $\left(V_{\mathrm{cl}}\right)$, as suggested by Uchida and others (1994a). Only by determining $y$ by other methods can the amount of air enclosed in the clathrates be calculated and compared with the total air volume, provided the volume estimates of the clathrates are correct. In our first neutron-diffraction studies, the site occupancy of guest molecules (values for oxygen clathrate as determined in the individual experiments; those for nitrogen clathrate were determined using the Langmuir constants taken from Kuhs and others, 1997) shows values of 0.83 at 120 bar for $\mathrm{O}_{2}$-clath- 


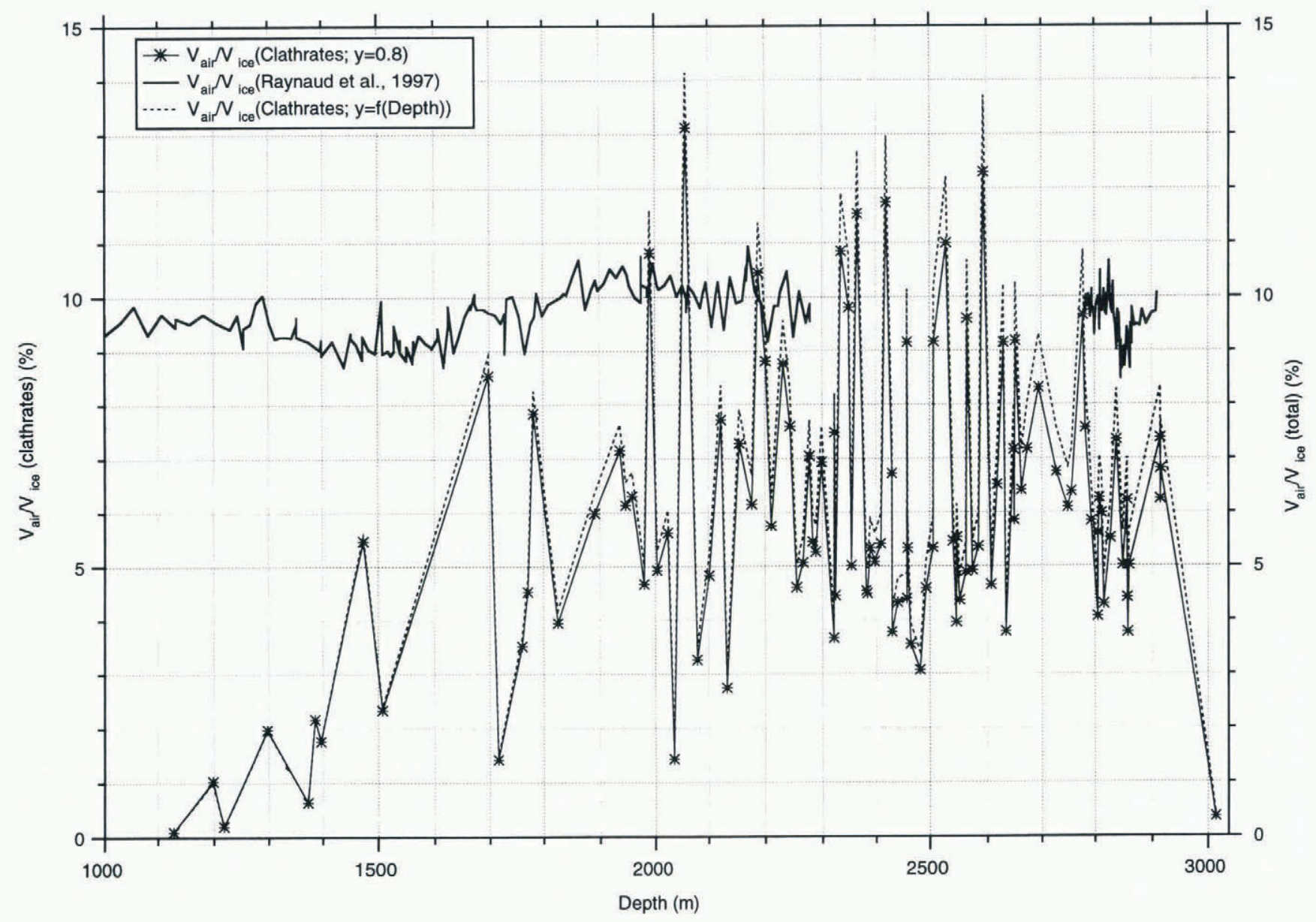

Fig. 6. Gas volume in clathrates $\left(V_{\text {gas }} / V_{\text {ice }}\right)$ and total gas volume; solid line and markers represent relative air concentration assuming a constant occupancy of $80 \%$; dashed line represents occupancy taking into account the pressure dependency according to Kuhs and others (1997).

rate and 0.84 at 155 bar for $\mathrm{N}_{2}$-clathrate; both pressures are close to the dissociation pressures of $\mathrm{O}_{2}$ - and $\mathrm{N}_{2}$-clathrate at 273.15 K (Kuhs and others, 1997). Assuming the degree of filling is similar near the dissociation pressures and temperatures we encounter in polar ice sheets, these values reflect the order of magnitude of the minimum value for $y$ in air clathrates, slightly greater than $80 \%$ as determined by Hondoh and others (1990). The degree of filling roughly follows a Langmuir isotherm (Van der Waals and Platteeuw, 1959) on the increase of pressure with depth, with occupancies of 0.93 for nitrogen and 0.90 for oxygen clathrate at a pressure of $330 \mathrm{bar}$, corresponding to pressures at the bottom of the core (about 300 bar), thus correcting $V_{\text {gas }} / V_{\text {ice }}$ to values of $7.0 \%$.

Even if we assume an occupancy of $100 \%$, we obtain an average of the gas content in the clathrates of $7.8 \%$, with the values for 88 samples still below the total gas content. However, a 100\% degree of filling cannot be assumed under the pressure-temperature conditions that are encountered in ice sheets. If we employ the Langmuir constants for nitrogen clathrates at $273.15 \mathrm{~K}$ obtained in the experiments published in Kuhs and others (1997), to calculate the degree of filling in the clathrates in the individual samples, we calculate an average gas concentration in the ice of $6.4 \pm 2.9 \%$ ). These values, however, give us only estimates. A correction for lower temperatures, as are present in ice sheets, must be applied, and it must be confirmed that the degree of filling for air clathrate is close to those of individual nitrogen and oxygen clathrates. These studies, to determine the degree of filling for synthetic air clathrates and at lower temperatures, are under way. As these investigations on synthetic clathrates to establish a relationship between cage occupancy and pressure-temperature have not been completed, we have employed the fixed value of $80 \%$ as determined by Hondoh and others (1990) for comparison with Uchida and others (1994a).

If the vertical dimension is taken to be as long as the longer horizontal one, the result is only a slightly greater total clathrate volume than in our initial calculation. It has to be stressed that most clathrates are spherical, whereas only a small proportion (about 10\%) consists of elongated ones.

This means that a significant amount of air has to be considered to be located outside the clathrates, which is even more pronounced in the samples from the deepest part of the core. Few clathrates $\left(<300 \mathrm{~cm}^{-3}\right)$ are observed below a depth of $2916 \mathrm{~m}$. Whereas the amounts of air extracted from this depth range exhibit normal values, the clathrate air contents in the samples around $2916 \mathrm{~m}$ show values of 6.2 $7.3 \%$; that from $3014 \mathrm{~m}$ depth shows an extremely low value of $0.37 \%$. The missing amount of air is assumed to be dissolved in the ice matrix.

\section{CONCLUSIONS}

Our observations have shown that the number-concentration profile of clathrates in deep ice cores is strongly influenced by climatic factors, with cold climate affording a higher clathrate-number concentration, so that climatic 
events can often be detected in the change of the clathratenumber concentration. Altogether, we have encountered 12 samples that contradict the observed trend, which corresponds to a proportion of less than $7 \%$. All of these show too few clathrates with respect to the above assumption. It is quite conceivable that other factors than temperature are responsible for the number concentration of clathrates, for example impurities, which in turn might be correlated with climate. On the other hand, it could be shown that a high number concentration of clathrates is encountered only during cold-climate stages.

The process of air-bubble/clathrate conversion has to be investigated in more detail to find out about climatic effects on the number concentration of bubbles and its consequences for the clathrate-number concentration. In particular, our future studies will have to focus on the question whether these can be directly correlated at all, or whether we have to establish a model describing the effect of climate on the clathrate formation after bubble close-off involving a separation of an individual bubble into more than one clathrate or a splitting of clathrates. Our first observations of the NGRIP ice core clearly point in this direction. At this stage, we cannot derive any correlation between climate and the number concentration of air bubbles from our statistical studies on clathrates.

The amount of air occluded in the clathrates appears to be systematically smaller than the total air content of polar ice. This suggests that a significant amount of air is dissolved in the ice matrix, which is in agreement with fractionation of atmospheric components in clathrates, as determined by Raman spectroscopy, and the theory of smaller clathrates disintegrating in the vicinity of larger specimens, which might involve diffusion of gases between these.

Growth processes of clathrates with progressive depth also seem to take place in Greenland's ice sheet, with a growth rate smaller than that for the Vostok core. Whether growth processes result from clathrate coalescence and/or from diffusion of gas molecules from smaller to larger clathrates, minimizing surface energies, is still an open question.

The disappearance of clathrates in the deepest parts of the core is a phenomenon that requires further attention. In these parts, a conspicuously large number of hexagonal platelet-like inclusions appear a certain time after core retrieval, depending on the storage conditions of the samples. Currently, it is uncertain what is contained in these inclusions, and whether or not there is a connection to the occurrence of clathrates or the diffusion of gases. A study on their nature and their occurrence is under way.

Although the studies carried out so far have established a relationship between the occurrence of clathrates and climate, many processes in polar ice sheets involving clathrate formation and subsequent transformation on their way down have not been elucidated. The first processes in this context start right after snow deposition, i.e. the impact of climate on the pore size and the composition of the gas in the open pores as a function of gravitational and ventilation effects. The gas composition in the air bubbles might already be different from the atmosphere of the time of the surrounding ice, but still undergoes further changes on the transformation to clathrates. At this stage, fractionation is arguably a function of the temperature at the depth of the formation of clathrates, with different $\mathrm{N}_{2} / \mathrm{O}_{2}$ ratios in ice from the same depth resulting from different depth at the time of nucleation and subsequent formation. But even after completion of clathrate formation, diffusion processes might lead to changes in the composition of clathrates and even their distribution, which is suggested by the trends in the number concentration and size of clathrates pointed out in this work and in Uchida and others (1994a).

Unfortunately, the investigation of the transition zone, which is most important for the understanding of the processes leading to fractionation of the atmospheric components and the relation between air bubbles and clathrates, is hampered by decomposition of many clathrates soon after core retrieval. Current and future deep ice-core drilling are providing the opportunity to overcome this difficulty by investigating this phenomenon right after core recovery. A number and size distribution of clathrates and air bubbles would have to be established in the field, before clathrates start to disintegrate. $\mathrm{An} \mathrm{N}_{2} / \mathrm{O}_{2}$ ratio distribution profile particularly in this part of the core is also desirable, but can, for reasons of logistics, only be carried out in laboratories after transportation of the samples from the drilling site. This would have to be done as soon as possible, meeting the optimum storage conditions of clathrates described in Uchida and others (1994e).

\section{ACKNOWLEDGEMENTS}

It would have been impossible to establish a depth profile involving so many samples without the help of several people. Thus, we would like to thank A. Frenzel, C. Spindeldreher, B. Heyen, J. Wrede, A. Ebbeler and A. Jaeschke for their part in sample preparation and clathrate evaluation. We thankJ. Chappellaz for providing the data on total gas content in the GRIP ice core.

This work is a contribution to the Greenland Ice Core Project (GRIP), which was coordinated and supported by the European Science Foundation. We thank the national funding organizations in Belgium, Denmark, France, Germany, Iceland, Italy, Switzerland and the U.K. and the Deutsche Forschungsgemeinschaft (DFG) for financial support. We also thank H. Narita, T. Hondoh and T. Uchida for many fruitful discussions. This paper is contribution No. 1292 of the Alfred-Wegener-Institut, Bremerhaven, Germany.

\section{REFERENCES}

Dansgaard, W. and 10 others. 1993. Evidence for general instability of past climate from a 250-kyr ice-core record. Nature, 364(6434), $218-220$.

Fukazawa, H., T. Ikeda, D. Suzuki, T. Hondoh, S. Mae and C. C. Langway, Jr. 1996a. Distribution of $\mathrm{N}_{2}$ and $\mathrm{O}_{2}$ within natural clathrate hydrate in polar ice sheets. In International Symposium on the Physics and Chemistry of Ice, 25-30 August 1996, Hanover, NH. Abstracts. Hanover, NH, U.S. Army Cold Regions Research and Engineering Laboratory, 120.

Fukazawa, H., T. Ikeda, T. Hondoh, P. Duval, V.Ya. Lipenkov and S. Mae. 1996b. Molecular fractionation of air constituent gases during crystal growth of clathrate hydrate in polar ice sheets. In Second International Conference on Natural Gas Hydrates, 2 - 6 June 1996, Toulouse. Proceedings. Toulouse, ENSIGC-INPT, 237-242.

Hondoh, T. 1996. Clathrate hydrates in polar ice sheets. In Second International Conference on. Natural Gas Hydrates, 2- 6 June 1996, Toulouse. Proceedings. Toulouse, ENSIGC-INPT, 131-138.

Hondoh, T., H. Anzai, A. Goto, S. Mae, A. Higashi and C. C. Langway, Jr. 1990. The crystallographic structure of the natural air-hydrate in Greenland Dye-3 deep ice core. 7. Incl. Phenom. Mol. Recog. Chem., $8(1-2), 17-24$.

Ikeda, T., T. Uchida and S. Mae. 1993. The effect of hydrostatic pressure on the formation of air-hydrate crystals. Proc. NIPR Symp. Polar Meteorol. Glaciol. 7, 1423.

Kuhs, W. F., B. Chazallon, G. Radaelli and F. Pauer. 1997. Cage occupancy 
and compressibility of deuterated $\mathrm{N}_{2}$-clathrate hydrate by neutron diffraction. J. Incl. Phenom. Mol. Recog. Chem., 29, 65-77.

Miller, S. L. 1969. Clathrate hydrates of air in Antarctic icc. Science, $165(3892), 489-490$.

Nakahara, J., Y. Shigesato, A. Higashi, T. Hondoh and C. C. Langway, Jr. 1988. Raman spectra of natural clathrates in deep ice cores. Philos. Mag. $B, 57(3), 421-430$.

Pauer, F., J. Kipfstuhl and W. F. Kuhs, 1995. Raman spectroscopic study on the nitrogen/oxygen ratio in natural ice clathrates in the GRIP ice core. Geophys. Res. Lett., 22 (8), 969 971.

Pauer, F., J. Kipfstuhl and W. F. Kuhs. 1996. Raman spectroscopic study on the spatial distribution of nitrogen and oxygen in natural ice clathrates and their decomposition to air bubbles. Geophys. Res. Lett., 23 (2), 177-180.

Pauer, F., J. Kipfstuhl and W. F. Kuhs. 1997. Raman spectroscopic and statistical studies on natural clathrates from the GRIP ice core, and neutron diffraction studies on synthetic nitrogen clathrates. 7. Geophys. Res., 102 (C12), 26,519-26,526.

Price, P. B. 1995. Kinetics of conversion of air bubbles to air hydrate crystals in Antarctic ice. Science, 267 (5205), $1802-1804$.

Raynaud, D. and R. Delmas. 1977. Composition des gaz contenus dans la glace polaire. International Association of Hydrological Sciences Publication 118 Symposium at Grenoble 1975 - Isotopes and Impurities in Snow and Ice), $377-381$.

Raynaud, D., J. Chappellaz, C. Ritz and P. Martinerie. 1997. Air content along the Greenland Ice Core Project core: a record of surface climatic parameters and elevation in central Greenland. 7. Geophys. Res., $102(\mathrm{Cl}), 26,607-26,613$.

Shoji, H. and C. C. Langway, Jr. 1982. Air hydrate inclusions in fresh ice core. Nature, 298 5874), 548-550.

Taylor, K. C. and 9 others. 1993. Electrical conductivity measurements from the GISP2 and GRIP Greenland ice cores. Nature, 366 (6455), 549-552.

Uchida, T., T. Hondoh, S. Mae, P. Duval and V.Ya. Lipenkov. 1992. In-situ observations of growth process of clathrate air-hydrates under hydrostatic pressure. In Maeno, N. and T. Hondoh, eds. Proceedings of the International Symposium on the Physics and Chemistry of Ice, Sapporo, Japan. Sapporo, Hokkaido University Press, 121-125.

Uchida, T., S. Mae, T. Hondoh, P. Duval and V.Ya. Lipenkov. 1993. Effects of air-hydrate crystals on ice grain growth. Proc. NIPR Symp. Polar Meleorol. Glaciol. 7, 7-13.

Uchida, T., T. Hondoh, S. Mae, V.Ya. Lipenkov and P. Duval. 1994a. Airhydrate crystals in deep ice-core samples from Vostok Station, Antarctica. f. Glaciol., 40 (134), 79-86.

Uchida, T., P. Duval, V.Ya. Lipenkov, T. Hondoh, S. Mae and H. Shoji. 1994b. Brittle zone and air-hydrate formation in polar ice sheets. Natl. Inst. Polar Res. Mem., Spec. Issue 49, 298-305.

Uchida, T., T. Hondoh, S. Mae, P. Duval and V.Ya. Lipenkov. 1994c. Effects of temperature and pressure on the transformation rate from air bubbles to air-hydrate crystals in ice sheets. Ann. Glaciol., 20, 143-147.

Uchida, T., S. Mae, T. Hondoh, V.Ya. Lipenkov and P. Duval. 1994d. Growth process of air-hydrates and diffusion of air molecules in deep ice sheet. Proc. NIPR Symp. Polar Meteorol. Glaciol. 8, 140-148.

Uchida, T., T. Hondoh, S. Mae, H. Shoji and N. Azuma. 1994e. Optimized storage condition of deep ice core samples from the viewpoint of air-hydrate analysis. Natl. Inst. Polar Res. Mem., Spec. Issue 49, 306-313.

Van Cleeff, A. and G. A. M. Diepen. 1960. Gas hydrates of nitrogen and oxygen. Recueil des Travaux Chimiques, 79, 582586.

Van Cleeff, A. and G. A. M. Diepen. 1965. Gas hydrates of nitrogen and oxygen II. Recueil des Travaux Chimiques, 84, 1085-1093.

Van der Waals, J. H. and J. C. Platteeuw. 1959. Clathrate solutions. Adv. Chem. Phys., 2(1), 1-57.

MS received 1 September 1997 and accepted in revised form 19 August 1998 